\title{
Dopaminergic Gene Polymorphisms Affect Long-term Forgetting in Old Age: Further Support for the Magnification Hypothesis
}

\author{
Goran Papenberg $^{1,2}$, Lars Bäckman ${ }^{2}$, Irene E. Nagel ${ }^{1,4}$, \\ Wilfried Nietfeld ${ }^{3}$, Julia Schröder ${ }^{3,5}$, Lars Bertram ${ }^{3}$, \\ Hauke R. Heekeren ${ }^{1,4}$, Ulman Lindenberger ${ }^{1}$, \\ and Shu-Chen $\mathrm{Li}^{1,6}$
}

\begin{abstract}
Emerging evidence from animal studies suggests that suboptimal dopamine (DA) modulation may be associated with increased forgetting of episodic information. Extending these observations, we investigated the influence of DA-relevant genes on forgetting in samples of younger ( $n=433,20$ 31 years $)$ and older $(n=690,59-71$ years $)$ adults. The effects of single nucleotide polymorphisms of the DA D2 (DRD2) and D3 (DRD3) receptor genes as well as the DA transporter gene (DAT1; SLC6A3) were examined. Over the course of one week, older adults carrying two or three genotypes associated with
\end{abstract}

\section{INTRODUCTION}

There are between-person differences in forgetting of episodic information over time that call for more exploration (MacDonald, Stigsdotter-Neely, Derwinger, \& Bäckman, 2006). Here, we specifically investigate on interindividual differences in the amount of forgetting after a retention interval of 1 week. Given the strong heritability of episodic memory (e.g., McClearn et al., 1997), we focused on genetic predispositions linked to dopaminergic systems as contributing factors to between-person heterogeneity in forgetting. Of special interest is whether potential genetic effects are greater in older than in younger adults.

\section{Dopaminergic Modulation of Episodic Memory}

Increasing evidence suggests that dopamine (DA) affects long-term memory formation and consolidation subserved by medial-temporal and fronto-striatal circuitries. Molecular imaging studies reveal strong links between DA receptor availability and measures of episodic memory.

\footnotetext{
${ }^{1}$ Max Planck Institute for Human Development, Berlin, Germany,

${ }^{2}$ Karolinska Institute, Stockholm, Sweden, ${ }^{3}$ Max Planck Institute for Molecular Genetics, Berlin, Germany, ${ }^{4}$ Freie Universität Berlin, ${ }^{5}$ Charité Universitätsmedizin, Berlin, Germany, ${ }^{6} \mathrm{TU}$ Dresden
}

higher DA signaling (i.e., higher availability of DA and DA receptors) forgot less pictorial information than older individuals carrying only one or no beneficial genotype. No such genetic effects were found in younger adults. The results are consistent with the view that genetic effects on cognition are magnified in old age. To the best of our knowledge, this is the first report to relate genotypes associated with suboptimal DA modulation to more long-term forgetting in humans. Independent replication studies in other populations are needed to confirm the observed association.
Specifically, higher DA D2 receptor binding in hippocampus has been related to better verbal (Takahashi et al., 2007) and pictorial (Takahashi et al., 2008) recall. Chen et al. (2005) reported a positive association between striatal D2 receptor availability and delayed memory after $30 \mathrm{~min}$. Also, D2 receptor availability in ventral striatum was positively associated with performance in tasks assessing word recognition, pattern recognition, and paired-associate learning (Cervenka, Bäckman, Cselényi, Halldin, \& Farde, 2008). Similarly, density of the striatal DA transporter (DAT) is related to episodic word recall and face recognition (ErixonLindroth et al., 2005).

Whereas these studies have established a strong link between DA and human episodic memory at short-term intervals, empirical evidence on the relation between DA and long-term forgetting in humans is scarce. In animals, however, research shows that an infusion of a DA antagonist affecting receptor mechanisms in the hippocampus impairs retention after longer, but not shorter, intervals (Bethus, Tse, \& Morris, 2010; O'Carroll, Martin, Sandin, Frenguelli, \& Morris, 2006). Further, findings from animal studies suggest that the persistence of fear memories depends on dopaminergic modulation long after the initial encounter with the fear-eliciting stimulus has occurred (Rossato, Bevilaqua, Izquierdo, Medina, \& Cammarota, 2009). Specifically, blocking receptors through a DA antagonist in the rat 
hippocampus $12 \mathrm{hr}$ after the initial fearful experience resulted in more memory decay 7 and 14 days later.

\section{Magnification of Genetic Effects in Old Age}

On the basis of the observation that the function relating DA signaling to cognitive performance is nonmonotonic (e.g., Vijayraghavan, Wang, Birnbaum, Williams, \& Arnsten, 2007; Mattay et al., 2003; Li \& Sikström, 2002), the resource modulation hypothesis (Lindenberger et al., 2008) states that genetic effects on cognition are likely to be larger in individuals with more constrained neuroanatomical or neurochemical resources. The hypothesis rests on the assumption that the function relating brain resources to cognitive performance is nonlinear; genetic variability is therefore more likely to result in performance differences when resources move away from close-to-optimal levels, as it does in normal aging (see Figure 1).

Initial evidence supports the resource modulation hypothesis of genetic effects on cognition. Using tasks assessing spatial working memory and executive functioning, Nagel et al. (2008) found that the effects of variation in the catechol-O-methyltransferase and brain-derived neurotrophic factor (BDNF) genes among older adults are magnified relative to younger adults: Carrying disadvantageous alleles of both genes resulted in poorer cognitive performance for older adults but not for the younger adults. Li, Chicherio, et al. (2010) investigated the effects of the BDNF gene and obtained an identical pattern of data in backward serial recall. Relatedly, an interactive effect of DAT (DAT1) and D2 receptor (DRD2) genotypes on backward serial recall was found to be larger in older than in younger adults (Li et al., 2013).

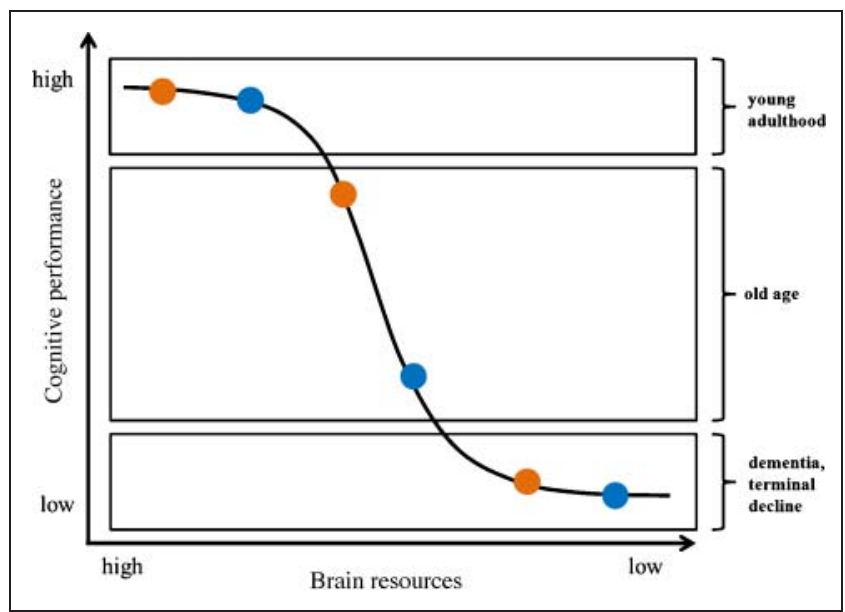

Figure 1. The resource modulation hypothesis predicts magnified genetic effects on cognitive performance in old age. As healthy aging is associated with decline in chemical and structural brain resources, constant amounts of genetic variation translate into increasingly larger performance differences. With resources further depleted, genetic effects are expected to diminish. The colored circles represent two individuals with different genetic predispositions as they move from early adulthood through old age to dementia and terminal decline (modified after Lindenberger et al., 2008).

\section{Aims and Key Hypotheses}

We explored whether individual differences in DA genes affect forgetting in samples of younger and older adults. Rather than focusing on a single gene, three genes that cover DA receptor and transporter functions were selected to capture individual differences in the efficacy of DA modulation. Specifically, we examined the effects of SNPs in the DA D2 (DRD2, C597T) and D3 (DRD3, Ser9Gly) receptor genes as well as the polymorphism of the DAT gene (DAT1, SLC6A3) on long-term forgetting. In humans, both DAT and D2-like receptors (i.e., the D2 and D3 receptor subtypes) are mainly expressed in subcortical regions, such as striatum and hippocampus (Schott et al., 2006; for a review, see Shohamy \& Adcock, 2010).

We hypothesized that individuals carrying more beneficial genotypes (see Methods for further details), presumably associated with higher synaptic DA and receptor availability, would forget less information from episodic memory over 1 week. Finally, given that human aging may magnify genetic effects (Li, Chicherio, et al., 2010; Lindenberger et al., 2008; Nagel et al., 2008), we expected that the DA genes would influence forgetting more in older than in younger adults.

\section{METHODS}

\section{Participants and Sample Inclusion Criteria}

A total of 445 younger (20-31 years, $53.7 \%$ women) and 783 older adults (59-71 years, 60.2\% women) were recruited via newspaper ads and posters posted in public transportation. All participants reported normal or corrected vision, were right-handed, as indexed by the Edinburgh Handedness Index (Oldfield, 1971), and had completed at least 8 years of education. Older participants scored over 27 on the Mini Mental Status Examination, which is a useful cutoff score to exclude individuals with mild cognitive impairment in highly educated elderly samples (O’Bryant et al., 2008). No participant was on medications that may affect memory, and none reported a history of head injuries or medical (e.g., heart attack), neurological (e.g., epilepsy), or psychiatric (e.g., depression) diseases. Written informed consent was obtained from all participants, who were paid for their participation. The ethics committees of the Charite University Medicine Berlin approved the study.

\section{Genotyping}

DNA was extracted from peripheral blood using standard methods. For the DAT gene (DAT1; SLC6A3), we genotyped the 40 base-pair variable number of tandem repeats (VNTR) in the $3^{\prime}$ untranslated region following common procedures (Vandenbergh et al., 1992). This polymorphism is characterized by a different number of tandem repeats, varying from 3 to 11 . In white participants, the most common genotypes (about 90\%) are 9-repeat homozygotes 
(9/9), 9-repeat/10-repeat heterozygotes (9/10), or 10-repeat homozygotes (10/10), with 10-repeat homozygotes being most frequent (Mitchell et al., 2000). The polymorphism of the DA D2 receptor gene (DRD2; C957T, rs6277) and the D3 receptor gene (DRD3; Ser9Gly, rs6280) were genotyped using commercially available allelic discrimination assays (C_11339240_10 for rs6277 and C_949770_10 for rs6280; TaqMan SNP genotyping Assay; Applied Biosystems, Forster City, CA) following previously described procedures (Livak, 1999). In white samples, DRD2 C/T heterozygotes are most frequent, followed by T/T homozygotes and $\mathrm{C} / \mathrm{C}$ homozygotes (Hirvonen, Lumme, et al., 2009). For the DRD3 gene, the most frequent genotype is $\mathrm{T} / \mathrm{T}$, followed by $\mathrm{C} / \mathrm{T}$ heterozygotes and $\mathrm{C} / \mathrm{C}$ homozygotes (Bombin et al., 2008).

The genotype frequencies in younger adults were DRD2-86:226:133 (C/C:C/T:T/T), DRD3-237:168:40 (T/T: C/T:C/C), and VNTR DAT1-25:174:246 (9/9:9/10:10/10). In the younger sample, all three polymorphisms were in Hardy-Weinberg equilibrium (HWE, all $\chi^{2}<1$, ps $>.05$ ). The corresponding distributions for the older sample were DRD2-189:359:235 (C/C:C/T:T/T), DRD3-389:334:60 (T/T:C/T:C/C), and VNTR DAT1-49:296:438 (9/9:9/ 10:10/10). In the older sample, the genotypic distributions for the DRD3 and DAT1 genotypes were within HWE $\left(\mathrm{DRD} 3: \chi^{2}(1)=1.02, p=.31\right.$ DAT1: $\chi^{2}(1)=0.02, p=$ .92). The DRD2 C957T polymorphism, however, mildly deviated from HWE $\left(\chi^{2}(1)=4.99, p=.03\right)$, reflecting a slightly higher frequency of T/T $(n=235$ vs. 219 , as expected by HWE) and C/C homozygotes ( $n=189$ vs. 173 , as expected by HWE) and a lower frequency of C/T heterozygotes ( $n=359$ vs. 390 , as expected by HWE).

\section{Defining Gene Score Groups}

To characterize individual differences in the efficacy of DA modulation in terms of transmitter availability and receptor density, we computed a gene score that corresponds to the number of beneficial genotypes of the three genes. Genotypes were defined as beneficial for memory consolidation if they have been associated with higher DA transmitter content (e.g., Heinz et al., 2000), higher receptor availability (e.g., Hirvonen, Lumme, et al., 2009), or better behavioral performance (e.g., Bombin et al., 2008; Roussos, Giakoumaki, \& Bitsios, 2008) in previous studies (see details below). Similar approaches using multiple genes have proven to be more predictive of the phenotypes of interest than focusing on single genes only (e.g., Hamrefors et al., 2010; de Quervain \& Papassotiropoulos, 2006). To group participants, we focused on beneficial homozygous genotypes instead of alleles, as the three genes may have differential effects on the DA systems and the behavioral phenotypes. Specifically, participants were categorized into two subgroups, namely, carriers of no or one beneficial homozygous genotype and carriers of two or three beneficial homozygous genotypes.
Individuals with three beneficial genotypes were extremely rare $(n=3$ in younger adults and $n=5$ in older adults). Therefore, carriers of two and three beneficial genotypes were grouped together and compared with the remaining sample. In the following, we refer to these groups as gene score groups. Next, the rationale behind the gene score grouping is described.

\section{DAT Gene (DAT1, SLC6A3) VNTR Polymorphism}

The VNTR polymorphism of the DAT1 gene affects DAT expression in vitro (Mill, Asherson, Browes, D'Souza, \& Craig, 2002) and in vivo (Heinz et al., 2000). The 9-repeat allele is associated with lower DAT expression. Consequently, 9-repeat carriers have higher availability of extrasynaptic DA. The highest amount of the DAT is expressed in striatum (Ciliax et al., 1999), and DAT is also expressed in hippocampus (Schott et al., 2006). Previous research has shown an advantage for 9-repeat carriers in executive functioning (Loo et al., 2003), working memory (Brehmer et al., 2009), and sequential learning (Simon et al., 2011). In an fMRI study, carriers of the DAT1 9-repeat allele showed higher midbrain activity during memory encoding than 10-repeat carriers (Schott et al., 2006). On the basis of these results, the 9/9 genotype was considered beneficial to memory performance and was assigned a score of 1 , whereas the 9/10 and 10/10 genotypes were assigned a score of 0 .

\section{C957T Polymorphism of the D2 Receptor Gene (DRD2)}

The C957T polymorphism of the human DRD2 gene (rs6277) affects the availability of DA D2 receptors in vivo. The $\mathrm{C} / \mathrm{C}$ genotype is associated with greater $\mathrm{D} 2$ receptor availability in extrastriatal regions (e.g., hippocampus; Hirvonen, Lumme, et al., 2009) as well as higher striatal DA content (Hirvonen, Laakso, et al., 2009; Hirvonen et al., 2004, 2005). On the basis of these results and previous findings showing that higher D2 receptor binding is associated with better episodic memory performance (e.g., Takahashi et al., 2008), the $\mathrm{C} / \mathrm{C}$ genotype was considered as beneficial and was assigned a score of 1 . The other two genotypes were assigned a score of 0 .

\section{Ser9Gly Polymorphism of the D3 Receptor Gene (DRD3)}

The DA D3 receptor is in the same family as the D2 receptor. The D3 receptor polymorphism Ser9Gly (rs6280) in exon 2 leads to a serine-to-glycine substitution at codon 9 (Lannfelt et al., 1992). This SNP has been studied most extensively in schizophrenia research (Nunokawa et al., 2010; Allen et al., 2008). Because of a lack of selective DA D3 receptor radioligands, currently, there are no in vivo studies relating variations in the DRD3 gene with D3 receptor density. However, results from a few studies 
involving cognitive functions suggest that the $\mathrm{T} / \mathrm{T}$ genotype of the DRD3 polymorphism is beneficial. These include research on executive functioning (Bombin et al., 2008), prepulse inhibition (Roussos et al., 2008), and an electroencephalographic study on attentional regulation (Mulert et al., 2006). Thus, the T/T variant of Ser9Gly in DRD3 was considered as beneficial and was assigned a score of 1 . The other genotypes were assigned a score of 0 .

\section{Experimental Task}

Participants underwent two cognitive testing sessions, 1 week apart. Each session lasted about 3 hr. Participants were tested in groups of about six individuals of the same age. The cognitive battery assessed episodic memory, working memory, executive functioning, perceptual speed, and psychometric measures of intelligence. Responses were made via button boxes and keyboards. The memory task of interest in this study is described below.

At the beginning of the first session, participants were presented with 48 complex, colored images consecutively of neutral emotional valence, at a rate of $3 \mathrm{sec} /$ scene. All pictures were derived from the International Affective Picture System (Lang, Bradley, \& Cuthbert, 1997). The images were encoded incidentally; during the study phase, participants were required to determine whether the scene was "indoor" or "outdoor" (24 indoor and 24 outdoor scenes were presented). The first recognition test was administered at the end of the first session after a delay of approximately $2.5 \mathrm{hr}$. The second recognition test was done 1 week later. During retrieval, participants viewed each image for 3 sec and were asked to determine whether the scene had been presented ("old") or not ("new") during encoding. In each recognition test, 24 unique old scenes and 24 unique new scenes (lures) were presented. The analysis was conducted on the proportion of hits minus false alarms (Macmillan \& Creelman, 2005).

\section{Data-based Exclusion Criteria}

Participants with negative hits minus false alarms and more than $20 \%$ of nonresponses in the task were excluded from analyses (7.8\% of the total sample), because this typically indicates that the task is not performed appropriately. Furthermore, outliers exceeding more than $\pm 4 S D$ in the behavioral measures were excluded ( $<1 \%$ of the total sample). This data-based exclusion of participants did not differ across gene score groups (younger adults: $\chi^{2}(1)=0.88$, $p>.10$; older adults: $\left.\chi^{2}(1)=0.07, p>.10\right)$. The effective sample consisted of 433 younger (53.6\% women) and 690 older (59.6\% women) adults. Table 1 presents descriptive statistics of demographic and self-reported health data across age and gene score group. Notably, the two gene score groups did not differ with respect to demographic and self-reported health data in either age group.

\section{Statistical Analyses and Covariates}

Behavioral data were analyzed with mixed-effect models ("Proc Mixed" procedure) using maximum-likelihood estimation in SAS 9.1 (SAS Institute, Inc., Cary, NC). In contrast to standard ANOVA, mixed-effect models do not assume equal variances and covariances between groups. This approach is more suitable here given multivariate heterogeneity of variances and covariances in the data, as reflected in the Box's M tests for recognition performance $(p=.01)$. Sex was used as a covariate to control for the well-established female advantage in episodic memory (e.g., Herlitz, Nilsson, \& Bäckman, 1997). In addition, analyses controlled for individual differences in the BDNF Val66Met (rs6265) genotype, because earlier studies have shown that this genotype affects episodic memory (Li, Chicherio, et al., 2010; Egan et al., 2003) and may interact with DA modulation (Nagel et al., 2008; Li, Cullen, Anwyl, \& Rowan, 2003). ${ }^{1}$ For all analyses, the alpha level was set at $p=.05$. Effect sizes are reported by the intraclass correlation coefficient (ICC), which is suitable for repeated measures designs (Fern \& Monroe,

Table 1. Demographic Variables and Self-reported Health across Age and Gene Score Group

\begin{tabular}{|c|c|c|c|c|}
\hline \multirow[b]{3}{*}{ Demographics } & \multicolumn{4}{|c|}{ Number of Beneficial Genotypes } \\
\hline & \multicolumn{2}{|c|}{ Younger Adults $(n=433)$} & \multicolumn{2}{|c|}{ Older Adults $(n=690)$} \\
\hline & $0 / 1(n=374)$ & $2 / 3(n=59)$ & $0 / 1(n=583)$ & $2 / 3(n=107)$ \\
\hline Age $(M \pm S D)$ & $26.1(3.0)$ & $26.5(2.9)^{\mathrm{a}}$ & $65.2(2.8)$ & $65.2(2.9)^{\mathrm{a}}$ \\
\hline Women/men & $171 / 203$ & $30 / 29^{b}$ & $231 / 352$ & $48 / 59^{\mathrm{b}}$ \\
\hline Years of education $(M \pm S D)$ & $12.5(1.2)$ & $12.9(1.5)^{\mathrm{a}}$ & $10.8(1.8)$ & $10.9(1.4)^{\mathrm{a}}$ \\
\hline State of health $(M \pm S D)$ & $3.9(0.6)$ & $3.9(0.6)^{\mathrm{a}}$ & $3.9(0.6)$ & $3.9(0.7)^{\mathrm{a}}$ \\
\hline
\end{tabular}

State of health is based on the mean of four self-ratings on 5-point scales $(1=$ poor, $5=$ excellent $)$.

${ }^{\mathrm{a}}$ One-way analyses of variance, $n s$.

${ }^{\mathrm{b}} \mathrm{\chi}^{2}=n s$. 
Figure 2. (A) Recognition memory performance after $2.5 \mathrm{hr}$ and 1 week for younger adults carrying no or one beneficial genotype $(n=374)$ and two or three beneficial genotypes $(n=59)$. (B) Recognition memory performance after $2.5 \mathrm{hr}$ and 1 week for older adults carrying no or one beneficial genotype $(n=583)$ and two or three beneficial genotypes $(n=107)$. Error bars represent one standard error around the means.

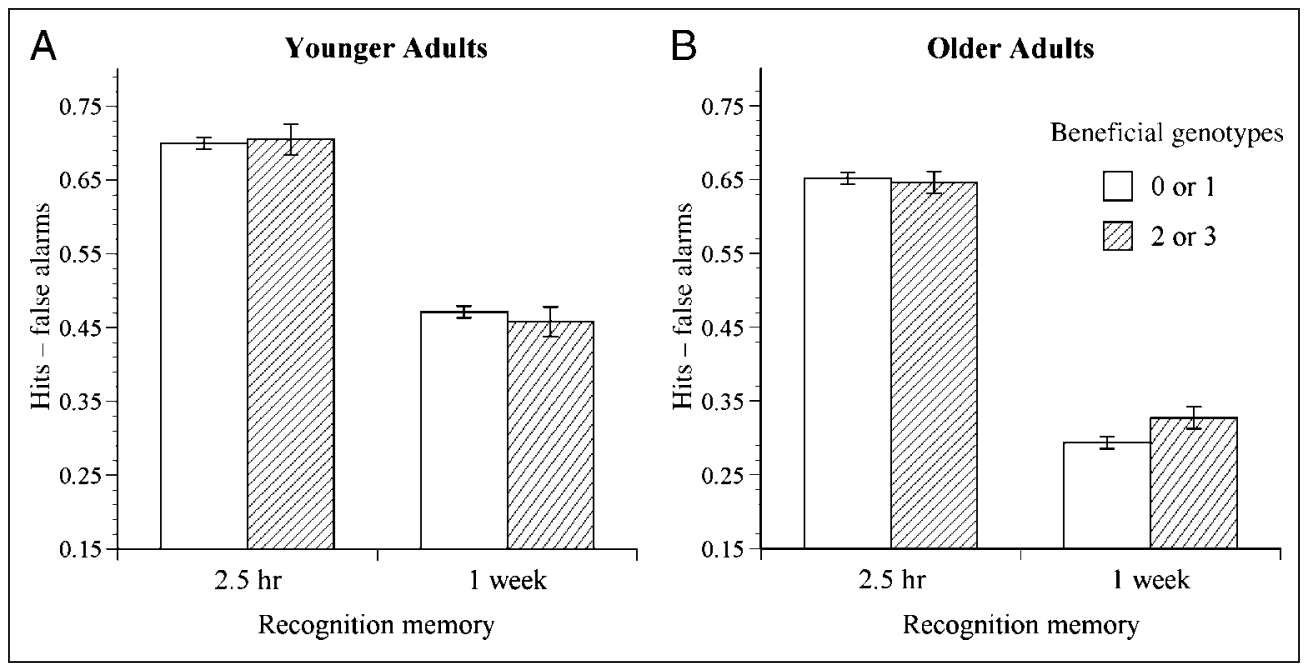

1996). The ICC values were squared to ease interpretation in terms of the percentage of total variance associated with an effect.

\section{RESULTS}

To investigate whether carrying more beneficial genotypes is related to less-pronounced forgetting, we conducted an omnibus test with age group (young vs. old) and gene score group (no or one beneficial genotype vs. two or three beneficial genotypes) as between-subject factors and session ( $2.5 \mathrm{hr}$ vs. 1 week) as a within-subject factor. As can be seen in Figure $2 \mathrm{~A}$ and B, both age groups showed marked forgetting after 1 week, indicating a main effect of Session, $F(1,180)=1494.14, p<.0001$, ICC $=0.945$, explaining $89.2 \%$ of the total variance in the data. Older adults performed worse than younger adults in both sessions, as indicated by a significant effect of Age Group, $F(1,159)=83.97, p<.0001$, ICC $=0.558$ (34.9\%). Furthermore, the Age group $\times$ Session interaction was significant, $F(1,180)=44.93, p<.0001$, ICC $=0.447(20.0 \%)$, reflecting more forgetting after 1 week in older than in younger adults. Critically, the interaction among Age Group, Gene Score Group, and Session was significant, $F(1,180)=$ $3.96, p=.048$, ICC $=0.147$ (2.2\%), indicating that older participants with at least two beneficial genotypes exhibited less forgetting after 1 week. Follow-up comparisons showed no differences between gene score groups after $2.5 \mathrm{hr}(\mathrm{ts}<1)$. However, older adults carrying fewer beneficial DA genotypes forgot more after 1 week than carriers of two or three beneficial genotypes $(t=-1.99, p=.048)$; whereas, there was no such gene score effect in younger adults $(t<1)$.

\section{DISCUSSION}

We investigated the effects of three DA-related genes (i.e., DAT1, DRD2, and DRD3) on episodic forgetting in younger and older adults. Individuals carrying fewer beneficial genotypes, indicating lower DA efficacy, were expected to forget more information after 1 week. In addition, based on the resource modulation model of the gene-cognition link (Lindenberger et al., 2008), we predicted stronger genetic effects in old age.

Our results show that greater availability of DA content and receptors, captured by a score based on the three DA genes, was related to less forgetting in older, but not in younger, adults. Interestingly, we did not observe genetic effects on recognition memory at a retention interval of $2.5 \mathrm{hr}$. This finding of individual differences in DA modulation predicting degree of forgetting in older adults is in line with animal data that DA antagonist infusion in the hippocampus impairs episodic memory to a larger degree after longer, as compared with shorter, retention intervals (de Lima et al., 2011; Bethus et al., 2010; Rossato et al., 2009; O'Carroll et al., 2006). Although DA modulation has been related to episodic memory performance in humans (e.g., Karlsson et al., 2011; Morcom et al., 2010; Cervenka et al., 2008; Takahashi et al., 2007, 2008; Bäckman et al., 2000), this is, to the best of our knowledge, the first time that suboptimal DA modulation has been related to more forgetting in a human sample.

In a recent study, we showed that older adults who fluctuated more from trial to trial in their RTs forgot more information after 1 week (Papenberg et al., 2011). Neurocomputational simulations (Li, Naveh-Benjamin, \& Lindenberger, 2005; Li \& Sikström, 2002; Li, Lindenberger, \& Sikström, 2001) suggest that suboptimal DA modulation results in a lower signal-to-noise ratio and less distinctive neural representations, which then lead to increased intraindividual variability and lower memory performance at the behavioral level. The picture drawn by these simulations is in line with data documenting that lower D2 receptor binding in prefrontal regions and hippocampus is associated with increased trial-to-trial RT variability (MacDonald, Cervenka, Farde, Nyberg, \& Bäckman, 2009). Further, two imaging studies reported better memory performance for rewarded than for nonrewarded stimuli after $24 \mathrm{hr}$ (Adcock, Thangavel, 
Whitfield-Gabrieli, Knutson, \& Gabrieli, 2006) and 3 weeks (Wittmann et al., 2005). In both studies, remembering reward-predicting items was associated with higher activity in midbrain DA regions during encoding, presumably enhancing hippocampal memory consolidation, as suggested in several animal studies (for reviews, see Lisman, Grace, \& Düzel, 2011; Lisman \& Grace, 2005).

Importantly, the observed genetic effects on forgetting were present in the older age group only. Thus, our results corroborate the resource modulation hypothesis, which predicts that genetic effects on cognition are more likely to be observed in populations with depleted structural and neuromodulatory brain resources, such as in older adults (Li et al., 2013; Li, Lindenberger, \& Bäckman, 2010; Lindenberger et al., 2008; Nagel et al., 2008). In view of the inverted U-shaped function relating DA signaling to cognitive performance (for reviews, see Cools \& D’Esposito, 2011; Lindenberger et al., 2008; Li \& Sikström, 2002), older adults with declining DA modulation (for reviews, see Bäckman, Lindenberger, Li, \& Nyberg, 2010; Bäckman, Nyberg, Lindenberger, Li, \& Farde, 2006) may benefit more from genetic predispositions associated with beneficial DA receptor and transporter functioning, relative to younger adults with more optimal DA levels (see Figure 1).

We focused on genes affecting DAT expression and D2 and D3 receptors, which were aggregated into a gene score. Conceivably, this approach captures interindividual differences in the efficacy of dopaminergic modulation more efficiently than a single-gene approach. Admittedly, the relative contributions of the different mechanisms associated with each of the contributing polymorphisms to the observed behavioral effects cannot be delineated with this approach. That said, individuals with more beneficial genotypes may be characterized by higher synaptic DA levels as well as higher receptor densities, both resulting in increased activation of D1 as well as D2 receptors, which have been shown to affect memory performance (e.g., Manago, Castellano, Oliverio, Mele, \& De Leonibus, 2009; Rossato et al., 2009; Mele et al., 1996; Castellano, Cestari, Cabib, \& Puglisi-Allegra, 1991) by facilitating and prolonging long-term potentiation (Manahan-Vaughan \& Kulla, 2003; Huang \& Kandel, 1995; Frey, Huang, \& Kandel, 1993).

As is common in behavioral genetic studies, the effect size observed in this study was relatively small (Payton, 2009; Barnett, Jones, Robbins, \& Müller, 2007). Future studies are needed to replicate these findings in independent data sets to substantiate the association between suboptimal DA modulation and forgetting.

Given that human episodic memory is a polygenetic trait (Rasch, Papassotiropoulos, \& de Quervain, 2010; de Quervain \& Papassotiropoulos, 2006), future research should also consider genes related to transmitter systems that are known to interact with DA systems in influencing molecular mechanisms underlying episodic memory. Examples include GABA (Swant, Stramiello, \& Wagner, 2008), glutamate (Cestari \& Castellano, 1997; Mele et al., 1996), acetylcholine (Fujishiro et al., 2005), and serotonin (PradoAlcalá et al., 2003) transmitter systems, all of which decline in old age (for reviews, see Eppinger, Hämmerer, \& Li, 2011; Magnusson, Brim, \& Das, 2010; Rissman, De Blas, \& Armstrong, 2007).

Our results provide novel information regarding the influence of DA-related genes on long-term forgetting of episodic information. Older adults with genetic predispositions associated with better DA efficacy forgot less pictorial information after 1 week. In younger age, no genetic effects were observed. These data extend previous observations of magnified genetic effects on cognition in old age.

\section{Acknowledgments}

This research was supported by the Max Planck Society, including grants from the innovation fund of the Max Planck Society (M.FE.Abild0005). It was also supported by a grant from the German Federal Ministry of Education and Research to the Berlin NeuroImaging Center (01G00501). L. B. was supported by the Swedish Research Council, Swedish Brain Power, an Alexander von Humboldt Research Award, and a donation from the af Jochnick Foundation. G. P. is a fellow of the International Max Planck Research School, The Life Course: Evolutionary and Ontogenetic Dynamics (LIFE). The authors thank Kirsten Becker, Ludmila Müller, Carolin Stockmeyer, and the other research assistants for their help.

Reprint requests should be sent to Goran Papenberg, Center for Lifespan Psychology, Max Planck Institute for Human Development, Lentzeallee 94, 14195 Berlin, Germany, or via e-mail: papenberg@ mpib-berlin.mpg.de.

\section{Note}

1. We also controlled for the effects of other memory-related genes including KIBRA (Kauppi, Nilsson, Adolfsson, Eriksson, \& Nyberg, 2011; Papassotiropoulos et al., 2006) and the serotonin receptor polymorphism 5-HTR2a gene (Schott et al., 2011; de Quervain et al., 2003). Including KIBRA as a covariate did not alter the pattern of results in the total sample. The 5-HTR2a gene was only available in a subsample of participants $(n=$ 692). Because there were so few younger persons with at least two beneficial genotypes $(n=21)$, we had to restrict the control analyses to the older adult sample. As with KIBRA, controlling for the 5-HTR2a gene did not affect the main pattern, namely that older adults with at least two beneficial genotypes forgot less after 1 week.

\section{REFERENCES}

Adcock, R. A., Thangavel, A., Whitfield-Gabrieli, S., Knutson, B., \& Gabrieli, J. D. E. (2006). Reward-motivated learning: Mesolimbic activation precedes memory formation. Neuron, 50, 507-517.

Allen, N. C., Bagade, S., McQueen, M. B., Ioannidis, J. P., Kavvoura, F. K., Khoury, M. J., et al. (2008). Systematic meta-analyses and field synopsis of genetic association studies in schizophrenia: The SzGene database. Nature Genetics, 40, 827-834.

Bäckman, L., Ginovart, N., Dixon, R. A., Robins Wahlin, T.-B., Wahlin, A., Halldin, C., et al. (2000). Age-related cognitive 
deficits mediated by changes in the striatal dopamine system. American Journal of Psychiatry, 157, 635-637.

Bäckman, L., Lindenberger, U., Li, S.-C., \& Nyberg, L. (2010). Linking cognitive aging to alterations in dopamine neurotransmitter functioning: Recent data and future avenues. Neuroscience \& Biobehavioral Reviews, 34 , 670-677.

Bäckman, L., Nyberg, L., Lindenberger, U., Li, S.-C., \& Farde, L. (2006). The correlative triad among aging, dopamine, and cognition: Current status and future prospects. Neuroscience E Biobehavioral Reviews, 30, 791-807.

Barnett, J. H., Jones, P. B., Robbins, T. W., \& Müller, U. (2007). Effects of the catechol-O-methyltransferase Val158Met polymorphism on executive function: A meta-analysis of the Wisconsin Card Sort Test in schizophrenia and healthy controls. Molecular Psychiatry, 12, 502-509.

Bethus, I., Tse, D., \& Morris, R. G. M. (2010). Dopamine and memory: Modulation of the persistence of memory for novel hippocampal NMDA receptor-dependent paired associates. Journal of Neuroscience, 30, 1610-1618.

Bombin, I., Arango, C., Mayoral, M., Castro-Fornieles, J., Gonzalez-Pinto, A., Gonzalez-Gomez, C., et al. (2008). DRD3, but not COMT or DRD2, genotype affects executive functions in healthy and first-episode psychosis adolescents. American Journal of Medical Genetics Part B: Neuropsychiatric Genetics, 147B, 873-879.

Brehmer, Y., Westerberg, H., Bellander, M., Fürth, D., Karlsson, S., \& Bäckman, L. (2009). Working memory plasticity modulated by dopamine transporter genotype. Neuroscience Letters, 467, 117-120.

Castellano, C., Cestari, V., Cabib, S., \& Puglisi-Allegra, S. (1991). Post-training dopamine receptor agonists and antagonists affect memory storage in mice irrespective of their selectivity for D1 or D2 receptors. Behavioral and Neural Biology, 56, 283-291.

Cervenka, S., Bäckman, L., Cselényi, Z., Halldin, C., \& Farde, L. (2008). Associations between dopamine D2-receptor binding and cognitive performance indicate functional compartmentalization of the human striatum. Neuroimage, $40,1287-1295$.

Cestari, V., \& Castellano, C. (1997). MK-801 potentiates morphine-induced impairment of memory consolidation in mice: Involvement of dopaminergic mechanisms. Psychopharmacology (Berlin), 133, 1-6.

Chen, P. S., Yang, Y. K., Lee, Y.-S., Yeh, T. L., Lee, I. H., Chiu, N. T., et al. (2005). Correlation between different memory systems and striatal dopamine D2/D3 receptor density: A single photon emission computed tomography study. Psychological Medicine, 35, 197-204.

Ciliax, B. J., Drash, G. W., Staley, J. K., Haber, S., Mobley, C. J., Miller, G. W., et al. (1999). Immunocytochemical localization of the dopamine transporter in human brain. Journal of Comparative Neurology, 409, 38-56.

Cools, R., \& D'Esposito, M. (2011). Inverted-u-shaped dopamine actions on human working memory and cognitive control. Biological Psychiatry, 69, e113-e125.

de Lima, M. N., Presti-Torres, J., Dornelles, A., Scalco, F. S., Roesler, R., Garcia, V. A., et al. (2011). Modulatory influence of dopamine receptors on consolidation of object recognition memory. Neurobiology of Learning and Memory, 95, 305-310.

de Quervain, D. J., Henke, K., Aerni, A., Coluccia, D., Wollmer, M. A., Hock, C., et al. (2003). A functional genetic variation of the 5-HT2a receptor affects human memory. Nature Neuroscience, 6, 1141-1142.

de Quervain, D. J., \& Papassotiropoulos, A. (2006). Identification of a genetic cluster influencing memory performance and hippocampal activity in humans Proceedings of the National Academy of Sciences, U.S.A., 103, 4270-4274.

Egan, M. F., Kojima, M., Callicott, J. H., Goldberg, T. E., Kolachana, B. S., Bertolino, A., et al. (2003). The BDNF val66met polymorphism affects activity-dependent secretion of BDNF and human memory and hippocampal function. Cell, 112, 257-269.

Eppinger, B., Hämmerer, D., \& Li, S.-C. (2011). Neuromodulation of reward-based learning and decision making in human aging. Annals of the New York Academy of Sciences, 1235, 1-17.

Erixon-Lindroth, N., Farde, L., Wahlin, T. B., Sovago, J., Halldin, C., \& Bäckman, L. (2005). The role of the striatal dopamine transporter in cognitive aging. Psychiatry Research, $138,1-12$.

Fern, E. F., \& Monroe, K. B. (1996). Effect-size estimates: Issues and problems in interpretation. Journal of Consumer Research, 23, 89-105.

Frey, U., Huang, Y.-Y., \& Kandel, E. R. (1993). Effects of cAMP simulate a late stage of LTP in hippocampal CA1 neurons. Science, 260, 1661-1664.

Fujishiro, H., Umegaki, H., Suzuki, Y., Oohara-Kurotani, S., Yamaguchi, Y., \& Iguchi, A. (2005). Dopamine D2 receptor plays a role in memory function: Implications of dopamine-acetylcholine interaction in the ventral hippocampus. Psychopharmacology (Berlin), 182, 253-261.

Hamrefors, V., Orho-Melander, M., Krauss, R. M., Hedblad, B., Almgren, P., Berglund, G., et al. (2010). A gene score of nine LDL and HDL regulating genes is associated with fluvastatin-induced cholesterol changes in women. Journal of Lipid Research, 51, 625-634.

Heinz, A., Goldman, D., Jones, D. W., Palmour, R., Hommer, D., Gorey, J. G., et al. (2000). Genotype influences in vivo dopamine transporter availability in human striatum. Neuropsychopharmacology, 22, 133-139.

Herlitz, A., Nilsson, L. G., \& Bäckman, L. (1997). Gender differences in episodic memory. Memory \& Cognition, 25, 801-811.

Hirvonen, M. M., Laakso, A., Någren, K., Rinne, J. O., Pohjalainen, T., \& Hietala, J. (2004). C957T polymorphism of the dopamine D2 receptor (DRD2) gene affects striatal DRD2 availability in vivo. Molecular Psychiatry, 9, 1060-1061.

Hirvonen, M., Laakso, A., Någren, K., Rinne, J. O., Pohjalainen, T., \& Hietala, J. (2005). Erratum: C957T polymorphism of the dopamine D2 receptor (DRD2) gene affects striatal DRD2 availability in vivo. Molecular Psychiatry, 10, 889.

Hirvonen, M. M., Laakso, A., Nagren, K., Rinne, J. O., Pohjalainen, T., \& Hietala, J. (2009). C957T polymorphism of dopamine D2 receptor gene affects striatal DRD2 in vivo availability by changing the receptor affinity. Synapse, 63, 907-912.

Hirvonen, M. M., Lumme, V., Hirvonen, J., Pesonen, U., Någren, K., Vahlberg, T., et al. (2009). C957T polymorphism of the human dopamine D2 receptor gene predicts extrastriatal dopamine receptor availability in vivo. Progress in Neuro-Psychopharmacology and Biological Psychiatry, 33, 630-636.

Huang, Y.-Y., \& Kandel, E. R. (1995). D1/D5 receptor agonists induce a protein synthesis-dependent late potentiation in the CA1 region of the hippocampus. Proceedings of the National Academy of Sciences, U.S.A., 92, 2446-2450.

Karlsson, S., Rieckmann, A., Karlsson, P., Farde, L., Nyberg, L., \& Bäckman, L. (2011). Relationship of dopamine D1 receptor binding in striatal and extrastriatal regions to cognitive functioning in healthy humans. Neuroimage, 57, 346-351. 
Kauppi, K., Nilsson, L. G., Adolfsson, R., Eriksson, E., \& Nyberg, L. (2011). KIBRA polymorphisma is related to enhanced memory and elevated hippocampal processing. Journal of Neuroscience, 31, 14218-14222.

Lang, P. J., Bradley, M. M., \& Cuthbert, B. N. (1997). International Affective Picture System (IAPS): Technical manual and affective ratings. Gainesville, FL: NIMH Center for the Study of Emotion and Attention, University of Florida.

Lannfelt, L., Sokoloff, P., Martres, M. P., Pilon, C., Giros, B., Jonsson, E., et al. (1992). Amino acid substitution in the dopamine D3 receptor as a useful polymorphism for investigating psychiatric disorders. Psychiatric Genetics, 2, 249-256.

Li, S., Cullen, W. K., Anwyl, R., \& Rowan, M. J. (2003). Dopamine-dependent facilitation of LTP induction in hippocampal CA1 by exposure to spatial novelty. Nature Neuroscience, 6, 526-531.

Li, S.-C., Chicherio, C., Nyberg, L., von Oertzen, T., Nagel, I. E., Papenberg, G., et al. (2010). Ebbinghaus revisited: Influences of the BDNF Val66Met polymorphism on backward serial recall are modulated by human aging. Journal of Cognitive Neuroscience, 22, 2164-2173.

Li, S.-C., Lindenberger, U., \& Bäckman, L. (2010). Dopaminergic modulation of cognition across the life span. Neuroscience E Biobehavioral Reviews, 34, 625-630.

Li, S.-C., Lindenberger, U., \& Sikström, S. (2001). Aging cognition: From neuromodulation to representation. Trends in Cognitive Sciences, 5, 479-486.

Li, S.-C., Naveh-Benjamin, M., \& Lindenberger, U. (2005). Aging neuromodulation impairs associative binding: A neurocomputational account. Psychological Science, 16, 445-450.

Li, S.-C., Papenberg, G., Nagel, I. E., Preuschhof, C., Schröder, J., Nietfeld, W., et al. (2013). Aging magnifies the effects of dopamine transporter and D2 receptor genes on backward serial memory. Neurobiology of Aging, 34, 358.e1-358.e10.

Li, S.-C., \& Sikström, S. (2002). Integrative neurocomputational perspectives on cognitive aging, neuromodulation, and representation. Neuroscience \& Biobehavioral Reviews, 26, 795-808.

Lindenberger, U., Nagel, I. E., Chicherio, C., Li, S.-C., Heekeren, H. R., \& Bäckman, L. (2008). Age-related decline in brain resources modulates genetic effects on cognitive functioning. Frontiers in Neuroscience, 2, 234-244.

Lisman, J. E., \& Grace, A. A. (2005). The hippocampal-VTA loop: Controlling the entry of information into long-term memory. Neuron, 46, 703-713.

Lisman, J. E., Grace, A. A., \& Düzel, E. (2011). A neoHebbian framework for episodic memory; role of dopaminedependent late LTP. Trend in Neurosciences, 34, 536-547.

Livak, K. J. (1999). Allelic discrimination using fluorogenic probes and the $5^{\prime}$ nuclease assay. Genetic Analysis, 14 , 143-149.

Loo, S. K., Specter, E., Smolen, A., Hopfer, C., Teale, P. D., \& Reite, M. L. (2003). Functional effects of the DAT1 polymorphism on EEG measures in ADHD. Journal of the American Academy of Child and Adolescents Psychiatry, 42, 986-993.

MacDonald, S. W. S., Cervenka, S., Farde, L., Nyberg, L., \& Bäckman, L. (2009). Extrastriatal dopamine D2 receptor binding modulates intraindividual variability in episodic recognition and executive functioning. Neuropsychologia, 47, 2299-2304.

MacDonald, S. W. S., Stigsdotter-Neely, A., Derwinger, A., \& Bäckman, L. (2006). Rate of acquisition, adult age, and basic cognitive abilities predict forgetting: New views on a classic problem. Journal of Experimental Psychology: General, 135, 368-390.
Macmillan, N. A., \& Creelman, C. D. (2005). Detection theory: A user's guide (2nd ed.). Mahwah, NJ: Lawrence Erlbaum Associates.

Magnusson, K. R., Brim, B. L., \& Das, S. R. (2010). Selective vulnerabilities of N-methyl-D-aspartate (NMDA) receptors during brain aging. Frontiers in Aging Neuroscience, 2, 11.

Manago, F., Castellano, C., Oliverio, A., Mele, A., \& De Leonibus, E. (2009). Role of dopamine receptors subtypes, D1-like and D2-like, within the nucleus accumbens subregions, core and shell, on memory consolidation in the one-trial inhibitory avoidance task. Learning \& Memory, 16, 46-52.

Manahan-Vaughan, D., \& Kulla, A. (2003). Regulation of depotentiation and long-term potentiation in the dentate gyrus of freely moving rats by dopamine D2-like receptors. Cerebral Cortex, 13, 123-135.

Mattay, V. S., Goldberg, T. E., Fera, F., Hariri, A. R., Tessitore, A., Egan, M. F., et al. (2003). Catechol O-methyltransferase val158-met genotype and individual variation in the brain response to amphetamine. Proceedings of the National Academy of Sciences, U.S.A., 100, 6186-6191.

McClearn, G. E., Johansson, B., Berg, S., Pedersen, N. L., Ahern, F., Petrill, S. A., et al. (1997). Substantial genetic influence on cognitive abilities in twins 80 or more years old. Science, 276, 1560-1563.

Mele, A., Castellano, C., Felici, A., Cabib, S., Caccia, S., \& Oliverio, A. (1996). Dopamine-N-methyl-D-aspartate interactions in the modulation of locomotor activity and memory consolidation in mice. European Journal of Pharmacology, 308, 1-12.

Mill, J., Asherson, P., Browes, C., D'Souza, U., \& Craig, I. (2002). Expression of the dopamine transporter gene is regulated by the $3^{\prime}$ UTR VNTR: Evidence from brain and lymphocytes using quantitative RT-PCR. American Journal of Medical Genetics, 114, 975-979.

Mitchell, R. J., Howlett, S., Earl, L., White, N. G., McComb, J., Schanfield, M. S., et al. (2000). Distribution of the $3^{\prime}$ VNTR polymorphism in the human dopamine transporter gene in world populations. Human Biology, 72, 295-304.

Morcom, A. M., Bullmore, E. T., Huppert, F. A., Lennox, B., Praseedom, A., Linnington, H., et al. (2010). Memory encoding and dopamine in the aging brain: A psychopharmacological neuroimaging study. Cerebral Cortex, 20, 743-757.

Mulert, C., Juckel, G., Giegling, I., Pogarell, O., Leicht, G., Karch, S., et al. (2006). A Ser9Gly polymorphism in the dopamine D3 receptor gene (DRD3) and event-related $\mathrm{P} 300$ potentials. Neuropsychopharmacology, 31, 1335-1344.

Nagel, I. E., Chicherio, C., Li, S.-C., von Oertzen, T., Sander, T., Villringer, A., et al. (2008). Human aging magnifies genetic effects on executive functioning and working memory. Frontier in Human Neuroscience, 2, 1.

Nunokawa, A., Watanabe, Y., Kaneko, N., Sugai, T., Yazaki, S., Arinami, T., et al. (2010). The dopamine D3 receptor (DRD3) gene and risk of schizophrenia: Case-control studies and an updated meta-analysis. Schizophrenia Research, 116, 61-67.

O'Bryant, S. E., Humphreys, J. D., Smith, G. E., Ivnik, R. J., Graff-Radford, N. R., Petersen, R. C., et al. (2008). Detecting dementia with the Mini-Mental State Examination (MMSE) in highly educated individuals. Archives of Neurology, 65, 963-967.

O'Carroll, C. M., Martin, S. J., Sandin, J., Frenguelli, B., \& Morris, R. G. M. (2006). Dopaminergic modulation of the persistence of one-trial hippocampus-dependent memory. Learning $\mathcal{E}$ Memory, 13, 760-769.

Oldfield, R. C. (1971). The assessment and analysis of handedness: The Edinburgh inventory. Neuropsychologia, 9, 97-113.

Papassotiropoulos, A., Stephan, D. A., Huentelman, M. J., Hoerndli, F. J., Craig, D. W., Pearson, J. V., et al. (2006). 
Common Kibra alleles are associated with human memory performance. Science, 314, 475-478.

Papenberg, G., Bäckman, L., Chicherio, C., Nagel, I. E., Heekeren, H. R., Lindenberger, U., et al. (2011). Higher intraindividual variability is associated with more forgetting and dedifferentiated memory functions in old age. Neuropsychologia, 49, 1879-1888.

Payton, A. (2009). The impact of genetic research on our understanding of normal cognitive ageing: 1995 to 2009. Neuropsychology Review, 19, 451-477.

Prado-Alcalá, R. A., Ruiloba, M. I., Rubio, L., Solana-Figueroa, R., Medina, C., Salado-Castillo, R., et al. (2003). Regional infusions of serotonin into the striatum and memory consolidation. Synapse, 47, 169-175.

Rasch, B., Papassotiropoulos, A., \& de Quervain, D. F. (2010). Imaging genetics of cognitive functions: Focus on episodic memory. Neuroimage, 53, 870-877.

Rissman, R. A., De Blas, A. L., \& Armstrong, D. M. (2007). GABAA receptors in aging and Alzheimer's disease. Neurochemistry, 103, 1285-1292.

Rossato, J. I., Bevilaqua, L. R. M., Izquierdo, I., Medina, J. H., \& Cammarota, M. (2009). Dopamine controls persistence of long-term memory storage. Science, 325, 1017-1020.

Roussos, P., Giakoumaki, S. G., \& Bitsios, P. (2008). The dopamine $\mathrm{D}(3)$ receptor Ser9Gly polymorphism modulates prepulse inhibition of the acoustic startle reflex. Biological Psychiatry, 64, 235-240.

Schott, B. H., Seidenbecher, C. I., Fenker, D. B., Lauer, C. J., Bunzeck, N., Bernstein, H.-G., et al. (2006). The dopaminergic midbrain participates in human episodic memory formation: Evidence from genetic imaging. Journal of Neuroscience, 26, 1407-1417.

Schott, B. H., Seidenbecher, C. I., Richter, S., Wüstenberg, T., Debska-Vielhaber, G., Schubert, H., et al. (2011). Genetic variation of the serotonin 2a receptor affects hippocampal novelty processing in humans. PLoS One, 18, e15984.

Shohamy, D., \& Adcock, R. A. (2010). Dopamine and adaptive memory. Trends in Cognitive Sciences, 14, 464-472.

Simon, J. R., Stollstorff, M., Westbay, L. C., Vaidya, C. J., Howard, J. H., Jr., \& Howard, D. V. (2011). Dopamine transporter genotype predicts implicit sequence learning. Behavior Brain Research, 216, 452-457.

Swant, J., Stramiello, M., \& Wagner, J. J. (2008). Postsynaptic dopamine D3 receptor modulation of evoked IPSCs via GABA(A) receptor endocytosis in rat hippocampus. Hippocampus, 18, 492-502.

Takahashi, H., Kato, M., Hayashi, M., Okubo, Y., Takano, A., Ito, H., et al. (2007). Memory and frontal lobe functions; possible relations with dopamine D2 receptors in the hippocampus. Neuroimage, 34, 1643-1649.

Takahashi, H., Kato, M., Takano, H., Arakawa, R., Okumura, M., Otsuka, T., et al. (2008). Differential contributions of prefrontal and hippocampal dopamine $\mathrm{D}(1)$ and $\mathrm{D}(2)$ receptors in human cognitive functions. Journal of Neuroscience, 28, 12032-12038.

Vandenbergh, D. J., Persico, A. M., Hawkins, A. L., Griffin, C. A., Li, X., Jabs, E. W., et al. (1992). Human dopamine transporter gene (DAT1) maps to chromosome 5p15.3 and displays a VNTR. Genomics, 14, 1104-1106.

Vijayraghavan, S., Wang, M., Birnbaum, S. G., Williams, G. V., \& Arnsten, A. F. (2007). Inverted-U dopamine D1 receptor actions on prefrontal neurons engaged in working memory. Nature Neuroscience, 10, 376-384.

Wittmann, B. C., Schott, B. H., Guderian, S., Frey, J. U., Heinze, H.-J., \& Düzel, E. (2005). Reward-related fMRI activation of dopaminergic midbrain is associated with enhanced hippocampus-dependent long-term memory formation. Neuron, 45, 459-467. 